\title{
Isolated night cough in children: how does it differ from wheeze?
}

\author{
Maja Jurca (10) ${ }^{1}$, Myrofora Goutaki (1) ${ }^{1,2}$, Philipp Latzin (1) ${ }^{2}$, Erol A. Gaillard ${ }^{3}$, \\ Ben D. Spycher ${ }^{1}$ and Claudia E. Kuehni (10 ${ }^{1,2}$
}

Affiliations: ${ }^{1}$ Institute of Social and Preventive Medicine, University of Bern, Bern, Switzerland. ${ }^{2}$ Paediatric Respiratory Medicine, Children's University Hospital of Bern, University of Bern, Bern, Switzerland. ${ }^{3}$ Division of Child Health, Dept of Infection, Immunity and Inflammation, University of Leicester, Leicester, UK.

Correspondence: Claudia E. Kuehni, Institute of Social and Preventive Medicine, University of Bern, Mittelstrasse 43, CH-3012 Bern, Switzerland. E-mail: claudia.kuehni囚ispm.unibe.ch

ABSTRACT It has been postulated that some children with recurrent cough but no wheeze have a mild form of asthma (cough variant asthma), with similar risk factors and an increased risk of future wheeze.

This longitudinal study compared risk factors for isolated night cough and for wheeze in the Leicester Respiratory Cohort in children aged 1, 4, 6 and 9 years and compared prognosis of children with isolated night cough, children with wheeze and asymptomatic children.

We included 4101 children aged 1 year, 2854 aged 4 years, 2369 aged 6 years and 1688 aged 9 years. The prevalence of isolated night cough was $10 \%$ at age 1 year and $18 \%$ in older children. Prevalence of wheeze decreased from $35 \%$ at 1 year to $13 \%$ at 9 years. Although several risk factors were similar for cough and wheeze, day care, reflux and family history of bronchitis were more strongly associated with cough, and male sex and family history of asthma with wheeze. Over one-third of preschool children with cough continued to cough at school age, but their risk of developing wheeze was similar to that of children who were asymptomatic at earlier surveys. Wheeze tracked more strongly throughout childhood than cough.

In conclusion, our study showed that only some risk factors for cough and wheeze were shared but many were not, and there was little evidence for an increased risk of future wheeze in children with isolated night cough. This provides little support for the hypothesis that recurrent cough without wheeze may indicate a variant form of asthma.

@ERSpublications

Children with isolated night cough do not have an increased risk of future wheeze, and risk factors for cough and wheeze only partially overlap. https://bit.ly/31IbXSC

Cite this article as: Jurca M, Goutaki M, Latzin P, et al. Isolated night cough in children: how does it differ from wheeze? ERJ Open Res 2020; 6: 00217-2020 [https://doi.org/10.1183/23120541.002172020].

This article has supplementary material available from openres.ersjournals.com.

Received: 26 April 2020 | Accepted after revision: 30 June 2020

Copyright $\odot$ ERS 2020. This article is open access and distributed under the terms of the Creative Commons Attribution Non-Commercial Licence 4.0. 


\section{Introduction}

Cough is common among children, accounts for many consultations and affects quality of life [1]. Most commonly caused by upper or lower respiratory tract infections, cough is usually self-limiting. However, some children cough frequently, also apart from infections [2, 3]. Many suffer from asthma and also report wheeze and shortness of breath. Other children have isolated frequent cough alone, without wheeze or dyspnoea $[4,5]$. It has been suggested that prolonged dry cough is a risk factor for asthma [6]. Some authors have gone further and postulated the existence of a specific asthma phenotype, called cough variant asthma (CVA) [7-9]. CVA has been described as a mild variant of asthma, where children present with cough as the sole symptom, instead of all three key symptoms of cough, wheeze and dyspnoea [10]. The following features have been described as typical for CVA: a family or personal history of atopy, eosinophilic inflammation, increased bronchial reactivity including positive exercise tests, a positive response to bronchodilators and an increased risk for developing wheeze or typical asthma later [9, 11-14].

The existence of CVA as a disease entity has been disputed and many maintain that isolated cough is a poor marker for asthma and should not be treated as such [8, 15-17]. The epidemiology of isolated cough, usually defined as night cough without colds, in children is not well studied. Previous publications included nonsystematic reviews [9, 18], small clinical studies with fewer than 50 patients [12, 19] or studies on adults $[20,21]$. Studies that compare children with isolated cough to children with wheeze and to asymptomatic children from the same population are scarce [16, 22, 23]. Drawing on the dataset from the 1998 Leicester Respiratory Cohort (LRC), we compared risk factors for isolated night cough and for wheeze, and we compared prognosis of children with isolated night cough, children with wheeze and those with neither symptom. This allowed us to investigate some of the proposed key features of CVA: risk factors typical for asthma, in particular a personal and family history of atopy and long-term prognosis (i.e. whether children with isolated night cough are at an increased risk for developing wheeze compared to asymptomatic children).

\section{Materials and methods}

Study design and population

We analysed data from a large, prospective population-based cohort, the LRC [24], which includes a large proportion of children of South Asian ethnic origin [25-27]. Perinatal and growth data were collected from birth records and health visitor records. The postal questionnaires collected information on cough, wheeze and environmental exposures from parents when children were aged 1 year (in 1998) and thereafter at the children's ages of 4 years (in 2001), 6 years (in 2003) and 9 years (in 2006). This study includes all LRC children who were born between May 1996 and April 1997 and who completed the baseline questionnaire in 1998 ( $\mathrm{n}=4101)$. Among these, $2854(70 \%)$ returned the questionnaire at age 4 years (in 2001), $2369(58 \%)$ at age 6 years (in 2003) and 1688 (41\%) at age 9 years (in 2006). The Leicestershire Health Authority Research Ethics Committee approved the study (approval nos. 1132, 5005 and 4867).

\section{Current wheeze and night cough}

We analysed replies to questions from the ISAAC key questionnaire [28], namely "In the last 12 months, has your child had a dry cough at night, apart from a cough associated with a cold or a chest infection?" and "Has your child had wheezing or whistling in the chest in the last 12 months?" We also asked each time: "In the last 12 months, did the following things cause your child to cough?" with answer categories including exercise (playing, running), laughing or crying, house dust, pollen (grass, hay, trees, flowers), contact with pets or other animals and food or drinks.

At each survey, we distinguished three mutually exclusive groups of children based on their symptoms during the previous 12 months: children with night cough but no wheeze (defined as isolated night cough), children with wheeze with or without cough and asymptomatic children with neither cough nor wheeze.

\section{Risk factors}

We compiled a list of potential risk factors for cough and wheeze from the literature [16, 22, 29], including demographic factors (sex, ethnicity), parental history of asthma, bronchitis, hay fever and eczema, exposure to infections (household crowding, day care attendance, older siblings), environmental exposures (cooking with gas, tobacco smoke exposure, pet ownership), socioeconomic factors (maternal education, Townsend deprivation index [30]) and perinatal/ early life factors (gestational age, birth weight, maternal age, breastfeeding, reflux in infancy). We also considered parent-reported clinical factors/ comorbidities, namely atopic diseases (rhinitis, hay fever, eczema) and ear, nose and throat (ENT) problems (frequent colds, snoring, otitis), as potential predictors of wheeze and cough at the next survey. Attendance at day care, reflux, ethnicity, family history, older siblings and perinatal and early life factors were only assessed at age 1 year in 1998 


\section{Statistical analyses}

We calculated the prevalence of isolated night cough and wheeze at ages 1, 4, 6 and 9 years, and then investigated risk factors for isolated night cough and wheeze at each age using multinomial logistic regression. We calculated univariable relative risk ratios (RRRs) with $95 \%$ confidence intervals (CIs) for isolated night cough and for wheeze compared to the reference category of asymptomatic children. In adjusted models, we included all risk factors that were associated with either cough or wheeze in the univariable model $(\mathrm{p}<0.1)$. We used Wald tests to compare whether RRRs differed between cough and wheeze.

We then investigated the prognosis of children with isolated night cough, wheeze and no symptoms by calculating the proportion of children who had the same phenotype at the next survey and the proportion who transitioned to another phenotype. We did this for the three different periods from ages 1 to 4 years, 4 to 6 years and 6 to 9 years. We used an overall Chi-squared test of independence between symptoms at baseline and symptoms at follow-up to assess whether prognosis differed between children with isolated night cough, children with wheeze and children with none of the symptoms, followed by a subgroup analysis to test whether children with isolated night cough had a higher risk of developing wheeze than asymptomatic children using Fisher's exact test.

Finally, we assessed potential predictors of prognosis (i.e. persistence of isolated night cough or incidence of wheeze 2-3 years later), in children with cough at baseline. Our main analysis included only children with isolated night cough at baseline and investigated potential predictors for isolated night cough and for wheeze at the next survey. In addition to environmental risk factors, we also investigated whether comorbidities at baseline (atopic diseases and ENT symptoms) predict outcome at the next survey [31]. The layout of our study is shown in figure 1 . In a sensitivity analysis we included both children with isolated night cough and asymptomatic children in the analysis and fitted a multivariable logistic regression with wheeze at the next survey as the dependent variable and isolated night cough at baseline as an additional independent variable. Variables associated $(\mathrm{p}<0.1)$ with the outcome in the univariable model were included in the multivariable model. We then applied backward selection to eliminate variables with $\mathrm{p}>0.1$ from the final model.

Further sensitivity analyses evaluated the robustness of our results. While the main analysis included all children, who participated in the baseline survey at the age of 1 year and one or more of the following surveys at 4,6 or 9 years, the sensitivity analysis included only children who participated in all four surveys (1318 children, 32\% of 4101). Results from this sensitivity analysis were similar to the main

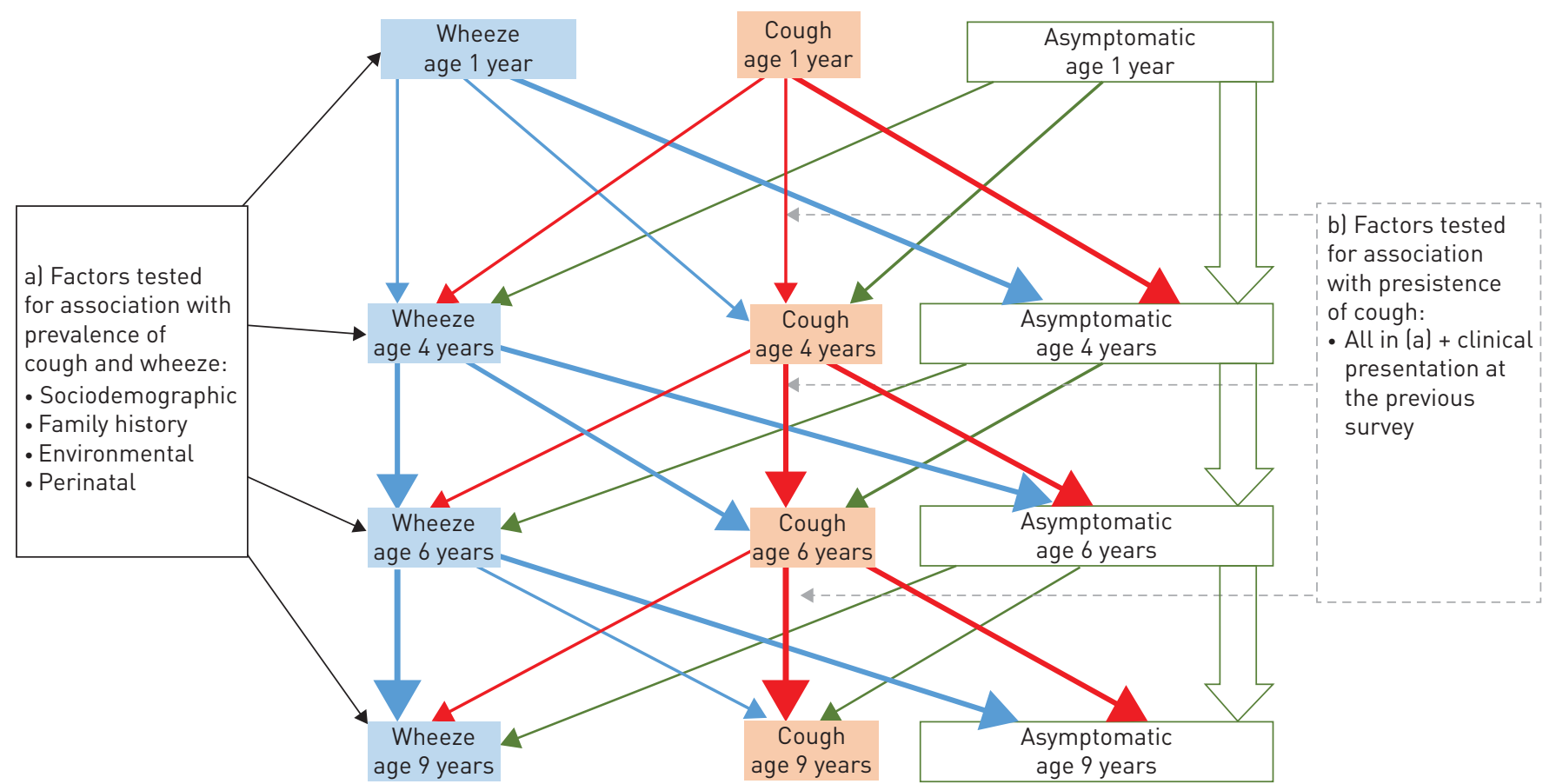

FIGURE 1 Study design: prevalence of wheeze and isolated cough at ages 1, 4, 6 and 9 years, and factors associated with prevalence and prognosis of these symptoms. The size of rectangular boxes represents the respective number of children with cough, wheeze or no symptoms, and the width of the arrows semi-quantitatively demonstrates the likelihood to stay in the same or change to a different group at subsequent surveys. 
analysis (available from the authors). We prepared and analysed the data using Stata 14.0 (Stata Corporation LP, Austin, TX, USA) and created the figures using R version 3.1.1 (Free Software Foundation, Boston, MA, USA).

\section{Results}

Among the 4101 participants of the 1998 survey, 3300 (80\%) were white British and 801 (20\%) were of South Asian ethnic origin (table 1). At the age of 1 year, $35 \%$ of parents reported that their child wheezed (with or without night cough), 23\% reported night cough, including $10 \%$ with isolated night cough (without wheeze). Prevalence of isolated night cough increased from 10\% in 1-year-olds to 18\% in 4-, 6and 9-year-olds (table S1). Prevalence of wheeze declined from 35\% in 1-year-olds to $17 \%$, $14 \%$, and $13 \%$ respectively in children aged 4,6 and 9 years.

\section{Risk factors for prevalent cough and wheeze}

Some risk factors were shared between children with isolated night cough and wheeze, but many differed and risk factors changed with age. Results are shown in table 2 for children aged 1 year and tables S2-S4

\section{TABLE 1 Characteristics of the study population at the age of 1 year, in $1998(n=4101)$}

n

\section{Demographic factors}

Ethnicity: South Asian White

Sex: boys

Girls

Family history \#

Asthma

Bronchitis

Hay fever

Eczema

Indoor exposures

Day care

Older siblings

Cooking with gas

Mother smoking

Father smoking

Any pets

Socioeconomic factors

Low maternal education"

Deprived (Townsend score $\geqslant 1.86)^{+}$

Perinatal and early life data

Preterm (gestational age $<37$ weeks)

Low birth weight $(<2500 \mathrm{~g})$

Young mother $(<25 \text { years })^{\S} \quad 929$

Child breastfed

Reflux (posseting) in infancy

Respiratory problems in the past year

Any night cough

Any wheeze

Isolated night cough

Cough triggered by: exercise

aeroallergens

laughter ${ }^{f}$

food

Rhinitis

Eczema $^{f}$

Frequent colds ( $>6$ episodes)

Snoring

Otitis

\section{1}

3300

2135

1966

1294

739

1846

1339

1030

2276

3051

895

1041

1664

1956

1303

893

929

3061

938

1420

427

408

77

727

427

1291

1155

777

2236

1706

\#: Either mother or father with a history of the disease; ": age at the end of education of mother is $\leqslant 16$ years; ${ }^{+}$: Townsend deprivation index (deprived, the highest two quintiles): deprived $(1.86,5.15)$, more deprived $(5.16,11.07) ;{ }^{\S}$ : when the child was born; ${ }^{f}$ : asked only in part of the cohort. Hay fever was not inquired about in the 1998 survey. 
TABLE 2 Risk factors for prevalence of isolated night cough and wheeze in 1-year-old children (n=4101). Association of different factors with cough and wheeze, compared to asymptomatic children, in an unadjusted and adjusted model presented as relative risk ratio estimates with confidence intervals. Cough was defined as night cough without wheeze.

\begin{tabular}{|c|c|c|c|c|c|c|}
\hline \multirow[t]{2}{*}{ Risk factors at age 1 year } & \multicolumn{3}{|c|}{ Unadjusted model } & \multicolumn{3}{|c|}{ Adjusted model ${ }^{\#}$} \\
\hline & $\begin{array}{l}\text { Night cough } \\
\text { RRR }(95 \% \text { CI) }\end{array}$ & $\begin{array}{c}\text { Wheeze } \\
\text { RRR }(95 \% \text { CI) }\end{array}$ & $\begin{array}{l}\text { Similarity } \\
\text { p-value }^{+}\end{array}$ & $\begin{array}{l}\text { Night cough } \\
\text { RRR }(95 \% \text { CI) }\end{array}$ & $\begin{array}{c}\text { Wheeze } \\
\text { RRR }(95 \% \text { CI) }\end{array}$ & $\begin{array}{l}\text { Similarity } \\
\text { p-value }^{+}\end{array}$ \\
\hline \multicolumn{7}{|l|}{ Demographic data } \\
\hline South Asian ethnicity & $1.3(1.0-1.6)$ & $0.6(0.5-0.8)$ & $<0.001$ & $1.4(1.0-2.0)$ & $0.8(0.6-1.0)$ & 0.001 \\
\hline Male sex & $0.9(0.7-1.1)$ & $1.3(1.1-1.5)$ & 0.003 & $0.9(0.7-1.2)$ & $1.3(1.2-1.6)$ & 0.003 \\
\hline \multicolumn{7}{|l|}{ Family history of ${ }^{\S}$} \\
\hline Asthma & $1.0(0.8-1.3)$ & $2.1(1.8-2.4)$ & $<0.001$ & $0.9(0.7-1.2)$ & $1.7(1.5-2.0)$ & $<0.001$ \\
\hline Bronchitis & $1.4(1.0-1.8)$ & $2.0(1.7-2.3)$ & 0.008 & $1.4(1.0-1.9)$ & $1.6(1.3-2.0)$ & 0.380 \\
\hline Hay fever & $1.2(1.0-1.4)$ & $1.5(1.3-1.7)$ & 0.049 & $1.1(0.9-1.4)$ & $1.2(1.1-1.4)$ & 0.407 \\
\hline Eczema & $1.1(0.8-1.3)$ & $1.3(1.1-1.5)$ & 0.109 & $1.0(0.8-1.3)$ & $1.0(0.8-1.1)$ & 0.702 \\
\hline \multicolumn{7}{|l|}{ Exposure to infections } \\
\hline Crowding & $1.1(0.9-1.4)$ & $1.2(1.1-1.4)$ & 0.322 & $1.1(0.8-1.4)$ & $1.1(0.9-1.3)$ & 0.961 \\
\hline Day care & $1.6(1.3-2.0)$ & $1.1(1.0-1.3)$ & 0.002 & $1.9(1.5-2.4)$ & $1.3(1.1-1.6)$ & 0.008 \\
\hline Older siblings & $0.9(0.7-1.1)$ & $1.2(1.0-1.4)$ & 0.019 & $0.9(0.7-1.2)$ & $1.3(1.1-1.6)$ & 0.008 \\
\hline \multicolumn{7}{|l|}{ Indoor exposures } \\
\hline Cooking with gas & $1.2(0.9-1.5)$ & $1.1(0.9-1.2)$ & 0.424 & & & \\
\hline Mother smoking & $1.1(0.8-1.4)$ & $1.8(1.6-2.2)$ & $<0.001$ & $1.1(0.8-1.5)$ & $1.4(1.2-1.7)$ & 0.104 \\
\hline Father smoking & $1.0(0.8-1.3)$ & $1.3(1.1-1.5)$ & 0.112 & $1.0(0.8-1.4)$ & $1.1(0.9-1.3)$ & 0.775 \\
\hline Pets & $0.8(0.7-1.0)$ & $1.1(1.0-1.3)$ & 0.006 & $0.9(0.7-1.2)$ & $1.1(0.9-1.2)$ & 0.273 \\
\hline \multicolumn{7}{|l|}{ Socioeconomic factors } \\
\hline Low maternal education ${ }^{f}$ & $1.0(0.8-1.3)$ & $1.3(1.1-1.4)$ & 0.056 & $1.1(0.9-1.4)$ & $1.0(0.9-1.2)$ & 0.613 \\
\hline Deprivation (Townsend) & $1.4(1.1-1.7)$ & $1.4(1.2-1.6)$ & 0.908 & $1.4(1.0-1.8)$ & $1.5(1.3-1.8)$ & 0.546 \\
\hline \multicolumn{7}{|l|}{ Perinatal and early life } \\
\hline Preterm (GA<37 weeks) & $0.8(0.5-1.3)$ & $1.2(0.9-1.6)$ & 0.096 & & & \\
\hline Low birthweight $(<2500 \mathrm{~g}$ ) & $0.8(0.5-1.3)$ & $1.1(0.9-1.5)$ & 0.187 & & & \\
\hline Young mother $(<25 \text { yrs })^{\# \#}$ & $1.2(0.9-1.5)$ & $1.5(1.3-1.8)$ & 0.048 & $1.1(0.8-1.5)$ & $1.4(1.2-1.7)$ & 0.091 \\
\hline Breastfeeding & $1.0(0.8-1.2)$ & $0.7(0.6-0.8)$ & 0.021 & $0.9(0.7-1.2)$ & $0.9(0.7-1.0)$ & 0.485 \\
\hline Reflux in infancy & $1.7(1.3-2.2)$ & $1.4(1.2-1.7)$ & 0.193 & $1.7(1.3-2.3)$ & $1.4(1.2-1.7)$ & 0.163 \\
\hline
\end{tabular}

for children aged 4, 6 and 9 years. The tables report RRRs for children with cough and children with wheeze compared to asymptomatic children and similarity p-values, which indicate the difference in strength of association with risk factors between cough and wheeze. Figures 2-4 and figure S1 summarise the same results graphically.

Factors that were equally important for both isolated night cough and wheeze were parental history of bronchitis, low socioeconomic status, exposure to smoking and reflux (posseting or vomiting, age 1 year). Factors that were associated mainly with isolated night cough were South Asian ethnicity, day care attendance (age 1 year), paternal smoking and use of gas for cooking (age 4 years). Several factors were more important for wheeze. Boys had a higher risk for wheeze at all ages, but a lower risk for cough at ages 6 and 9 years. A family history of asthma or hay fever was associated with wheeze only. Maternal smoking and presence of older siblings were more strongly associated with wheeze at age 1 year. Low birthweight, preterm birth and lack of breastfeeding were associated mainly with wheeze. Similarity p-values suggested that associations differed significantly between wheeze and cough for sex and family history of asthma at all ages; ethnicity, day care attendance and older siblings at age 1 year; and cooking with gas, exposure to smoking, low socioeconomic status and preterm birth at age 4 years (table 2 and tables S2-S4).

\section{Prognosis of isolated night cough and wheeze}

Prognosis differed between children with wheeze, those with isolated night cough and those who had no such symptoms for all intervals studied from ages 1 to 4 years, 4 to 6 years and 6 to 9 years (overall p-values $<0.001$, figure 5 and table S5). The proportion of children with isolated night cough, whose cough 


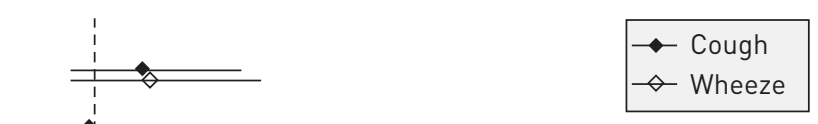

South Asian
Male sex
Family history of asthma
Bronchitis
Hay fever
Eczema
Crowding
Day care
Cooking gas
Mother smoking
Father smoking
Low maternal education
Deprivation (Townsend)
Low birthweight
Young mother
Breastfeeding
Reflux in infancy
Family history of asthma
ronchitis
y fever
czema
ay care
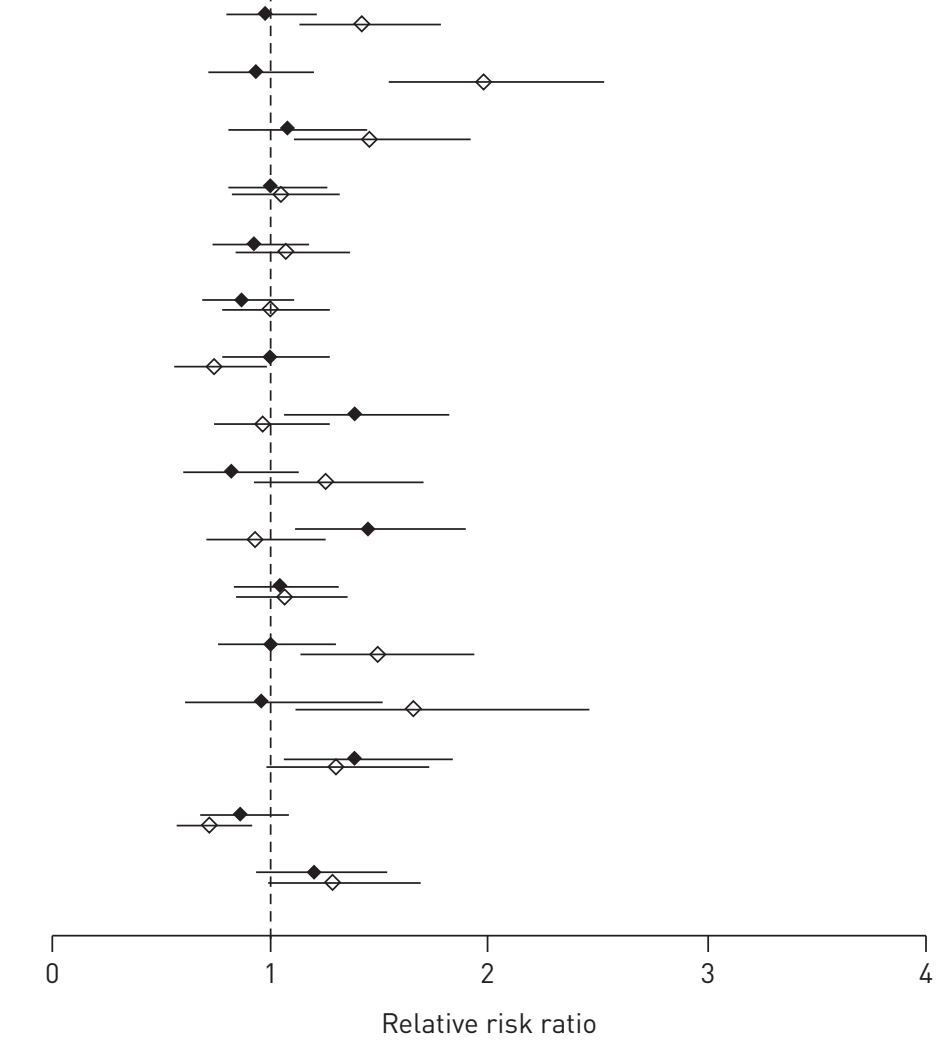

FIGURE 2 Risk factors for prevalent isolated night cough and wheeze at age 4 years $(n=2854)$. Association of different factors with cough and with wheeze, compared to asymptomatic children, in a fully adjusted model ladjusted for all covariates with $p$-values $<0.1$ for either cough or wheeze in univariable models), presented as relative risk ratio estimates with confidence intervals. Cough was defined as night cough without wheeze.

persisted, increased from 32\% (99 of 305) between age 1 and 4 years, to 42\% (160 of 381) from age 4 to 6 years and 39\% (97 of 249) from age 6 to 9 years. Wheeze was more persistent than isolated night cough. Among children with wheeze at age 1 year, 31\% (283 of 921) wheezed at age 4 years. Among 4 -year-olds with wheeze, $48 \%$ (151 of 315) wheezed again at age 6 years and among 6-year-olds with wheeze, $59 \%$ (98 of 165) reported wheeze at age 9 years.

The risk of developing new (incident) wheeze at the next survey was not higher in children with isolated night cough than in asymptomatic children, with the exception of infants, among whom $17 \%$ of those with isolated night cough reported wheeze 3 years later compared to $9 \%$ of asymptomatic children $(p<0.001)$. In children aged 4 or 6 years, we found no evidence that the risk of wheeze at the next survey differed between children with isolated night cough and asymptomatic children ( $p$-values 0.133 and 0.071 respectively). The sensitivity analysis (the multivariable regression based on data from both asymptomatic children and children with isolated night cough; table S6) yielded comparable results. Isolated night cough was associated with future wheeze in 1-year-olds (OR 2.2 (95\% CI 1.5-3.1)), but not in 4-year-olds (1.2 $(0.7-2.1))$ or 6 -year olds $(1.4(0.8-2.5))$. The associations with the other risk factors in the multivariable model were largely comparable to the univariable analysis from table 3 ; in particular incident wheeze was associated with male sex in all age groups and with day care and maternal smoking at age 1 year, a high Townsend score at age 1 year, cooking with gas and low maternal education at age 6 years and rhinitis and snoring at age 6 years.

\section{Predictors of future symptoms in children with cough}

Factors associated with prognosis in children with isolated night cough are shown in table 3. Some factors were associated with both persistence of isolated night cough and development of wheeze, but more strongly with wheeze. These included cough triggered by laughter (4 to 6 years) or by aeroallergens (6 to 9 years) and hay fever (6 to 9 years). Persistence of isolated night cough was not strongly associated with 


South Asian
Male sex
Family history of asthma
Bronchitis
Hay fever
Eczema
Crowding
Mother smoking
Low maternal education
Deprivation (Townsend)
Pre-term
Low birthweight
Young mother

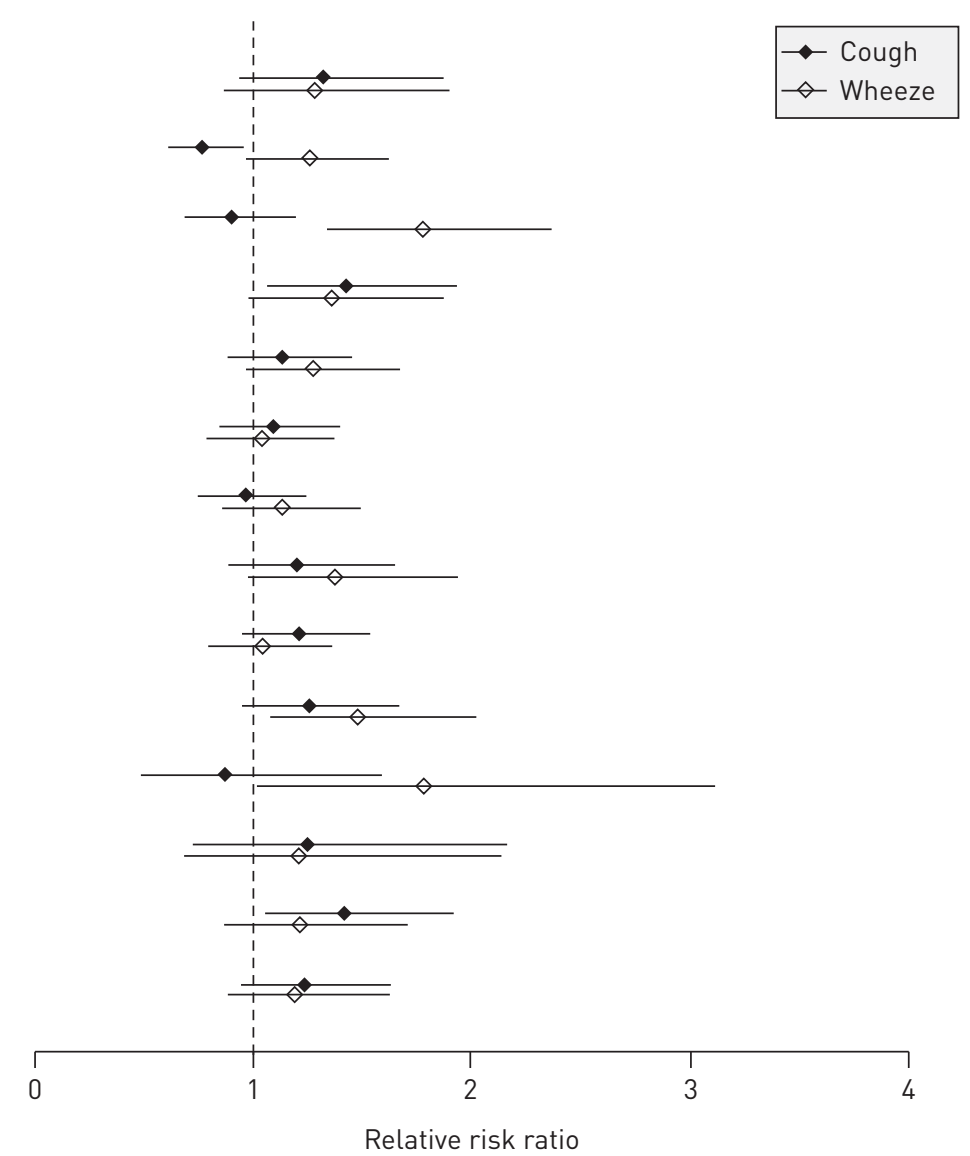

Reflux infancy

FIGURE 3 Risk factors for prevalent isolated night cough and wheeze at age 6 years $(n=2369)$. Association of different factors with cough and with wheeze, compared to asymptomatic children, in a fully adjusted model ladjusted for all covariates with $p$-values $<0.1$ for either cough or wheeze in univariable models), presented as relative risk ratio estimates with confidence intervals. Cough was defined as night cough without wheeze.

any of the tested environmental or perinatal factors from ages 1 to 4 years, 4 to 6 years or 6 to 9 years (table 3). Comorbidities were helpful in older children: persistence of isolated night cough from age 4 to 6 years was predicted by rhinitis, cough triggered by laughter/ crying and snoring at age 4 years; persistence of isolated night cough from age 6 to 9 years was predicted by frequent infections (frequent colds, otitis) or allergies (hay fever, cough triggered by aeroallergens) at age 6 years.

Some factors were associated with progression from isolated night cough to wheeze, particularly in older children. Children with isolated night cough who had a family history of asthma had an increased risk of later wheeze in all age groups. Children whose isolated night cough was triggered by aeroallergens or by laughter/ crying at age 4 years had an increased risk of wheeze at age 6 years. Children who had also rhinitis, hay fever, eczema, cough triggered by aeroallergens, snoring or exposure to pets at age 6 years had an increased risk of incident wheeze at age 9 years (table 3 ).

\section{Discussion}

This large population-based study compared risk factors and prognosis of isolated night cough with wheeze in different age groups from infancy to school age. It found that some risk factors were shared for cough and wheeze, whereas surprisingly many differed. A family history of asthma was more closely associated with wheeze in all age groups. Male sex was only associated with wheeze, perhaps because of the so-called dysanapsis, causing young boys to have smaller airways relative to lung size than girls [32,33]. On the other hand, reflux and day care in infancy and environmental exposures such as gas cookers and parental smoking were more strongly associated with isolated night cough than with wheeze. Wheeze persisted more than cough, and persistence was higher in older children. With the possible exception of 1-year-olds, we found no clear evidence that children with isolated night cough had a higher risk to develop wheeze than asymptomatic children.

Risk factors for cough have been little studied, mainly in clinical settings [1,34,35] and rarely in the general population $[16,22]$. A cross-sectional Danish study of 2978 5-year-olds reported male sex, low 
South Asian

Male sex

Family history of asthma

Bronchitis

Hay fever

Cooking gas

Father smoking

Pets

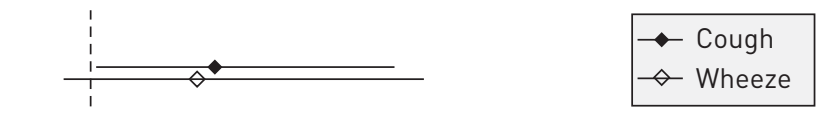

Deprivation (Townsend)

Pre-term

Low birthweight

Young mother

Breastfeeding

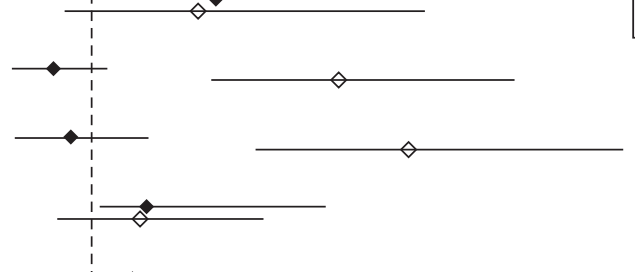

Wheez
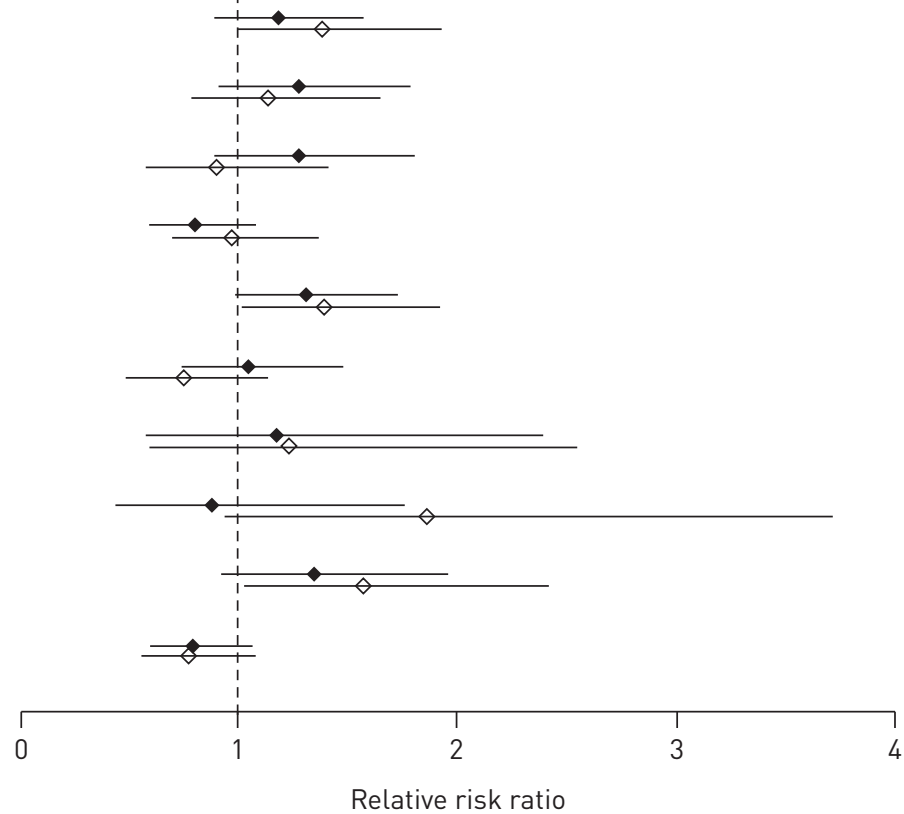

FIGURE 4 Risk factors for prevalent isolated night cough and wheeze at age 9 years ( $n=1688$ ). Association of different factors with cough and with wheeze, compared to asymptomatic children, in a fully adjusted model ladjusted for all covariates with $\mathrm{p}$-values $<0.1$ for either cough or wheeze in univariable models), presented as relative risk ratio estimates with confidence intervals. Cough was defined as night cough without wheeze.

gestational age, maternal asthma and housing conditions as risk factors for wheeze, but not for isolated cough without colds [22]. The Tucson Children's Respiratory Study of 987 6-year-olds, identified parental history of bronchitis and passive smoking as risk factors for cough without colds [16]. Passive smoking and day care attendance were reported as risk factors for isolated night cough by other studies [36-38]. A Finnish study reported that 7 to 12 -year-olds with isolated night cough had an intermediate prevalence of parental asthma and allergies compared to children with wheeze and asymptomatic children and suggested that this supports the existence of CVA [39]. In contrast, a cross-sectional Australian study of 1165 school children found no differences between children with isolated night cough and asymptomatic

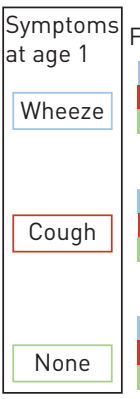

Follow up at age 4 years
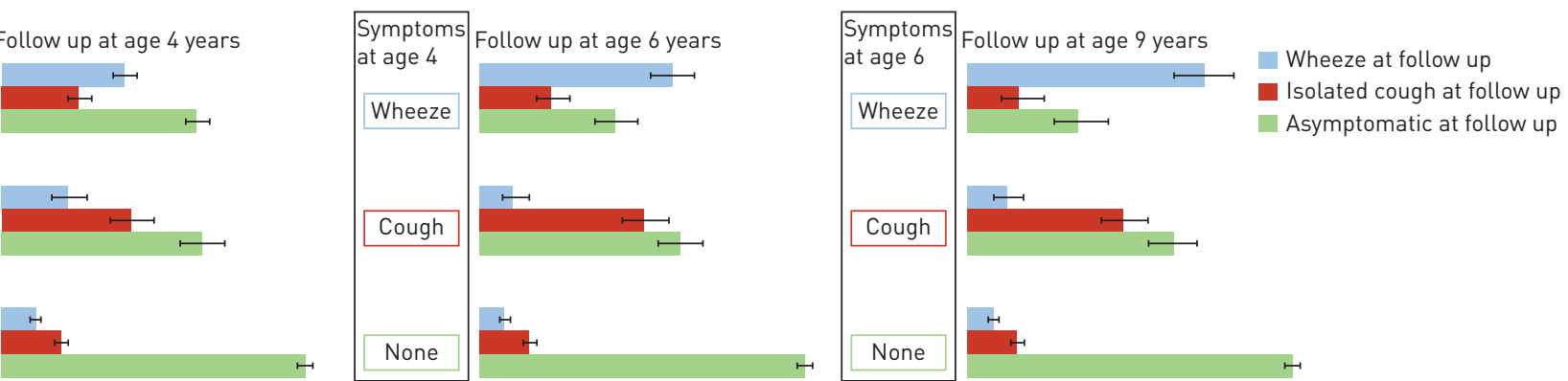

$0 \% 10 \%$ 20\% $30 \% 40 \% 50 \% 60 \% 70 \% 80 \% 90 \% 100 \%$

$0 \% 10 \% 20 \% 30 \% 40 \% 50 \% 60 \% 70 \% 80 \% 90 \% 100 \%$

$0 \% 10 \% 20 \% 30 \% 40 \% 50 \% 60 \% 70 \% 80 \% 90 \% 100 \%$

FIGURE 5 Prognosis and tracking of respiratory symptoms in children. Proportion of children with wheeze, isolated night cough or none of the symptoms, who have wheeze, cough or are asymptomatic 2-3 years later. This figure shows prognosis for three different development periods in childhood ( 1 to 4 years, 4 to 6 years and 6 to 9 years). 
TABLE 3 Predictors of future symptoms in children with isolated night cough at baseline for different age intervals (from age 1 to 4 years, from age 4 to 6 years and from age 6 to 9 years). Example for the youngest age group: in children with isolated night cough at age 1 year, what are the factors associated with persistence of isolated night cough versus incidence of wheeze at age 4 years? The presented associations are univariable.

\begin{tabular}{|c|c|c|c|c|c|c|c|c|c|}
\hline \multirow[t]{2}{*}{ Risk factors at baseline } & \multicolumn{3}{|c|}{ From age 1 to 4 years $(n=305)$} & \multicolumn{3}{|c|}{ From age 4 to 6 years $(n=381)$} & \multicolumn{3}{|c|}{ From age 6 to 9 years $(n=249)$} \\
\hline & $\begin{array}{l}\text { Night cough" } \\
\text { RRR }(95 \% \text { CI) }\end{array}$ & $\begin{array}{c}\text { Wheeze } \\
\text { RRR }(95 \% \text { CI) }\end{array}$ & $\begin{array}{l}\text { Similarity } \\
\text { p-value }\end{array}$ & $\begin{array}{l}\text { Night cough" } \\
\text { RRR }(95 \% \text { CI) }\end{array}$ & $\begin{array}{c}\text { Wheeze } \\
\text { RRR }(95 \% \text { CI) }\end{array}$ & $\begin{array}{l}\text { Similarity } \\
\text { p-value }\end{array}$ & $\begin{array}{l}\text { Night cough } \\
\text { RRR }(95 \% \text { CI) }\end{array}$ & $\begin{array}{c}\text { Wheeze } \\
\text { RRR }(95 \% \text { CI) }\end{array}$ & $\begin{array}{l}\text { Similarity } \\
\text { p-value }\end{array}$ \\
\hline South Asian ethnicity & $1.0(0.5-1.8)$ & $1.3(0.6-2.7)$ & 0.412 & $1.2(0.7-2.2)$ & $1.8(0.7-4.5)$ & 0.380 & $1.1(0.5-2.2)$ & $0.7(0.2-2.5)$ & 0.486 \\
\hline Male sex & $0.8(0.5-1.3)$ & $1.6(0.9-3.1)$ & 0.037 & $0.7(0.5-1.1)$ & $1.7(0.8-3.7)$ & 0.029 & $0.8(0.5-1.4)$ & $2.2(0.9-5.6)$ & 0.036 \\
\hline \multicolumn{10}{|l|}{ Family history of } \\
\hline Asthma & $1.2(0.7-2.3)$ & $3.0(1.5-6.0)$ & 0.018 & $1.3(0.8-2.0)$ & $2.3(1.1-5.0)$ & 0.127 & $1.0(0.5-1.8)$ & $3.4(1.4-8.2)$ & 0.009 \\
\hline Bronchitis & $0.7(0.4-1.4)$ & $1.4(0.7-3.0)$ & 0.112 & $1.1(0.6-1.9)$ & $1.1(0.4-2.8)$ & 0.988 & $1.5(0.7-2.9)$ & $1.8(0.6-5.0)$ & 0.724 \\
\hline Hay fever & $0.9(0.6-1.5)$ & $1.3(0.7-2.5)$ & 0.288 & $1.3(0.8-1.9)$ & $1.8(0.9-3.9)$ & 0.350 & $1.7(1.0-2.9)$ & $1.6(0.7-3.8)$ & 0.895 \\
\hline Eczema & $1.2(0.7-2.0)$ & $1.0(0.5-1.9)$ & 0.598 & $1.4(0.9-2.2)$ & $1.8(0.8-4.0)$ & 0.472 & $0.6(0.3-1.0)$ & $0.8(0.3-1.9)$ & 0.538 \\
\hline \multicolumn{10}{|l|}{ Exposure to infections } \\
\hline Crowding & $1.0(0.6-1.8)$ & $1.4(0.7-2.7)$ & 0.425 & $0.9(0.5-1.4)$ & $1.5(0.7-3.4)$ & 0.179 & $1.1(0.6-1.8)$ & $1.1(0.4-2.7)$ & 0.953 \\
\hline Day care at age 1 year & $1.2(0.6-2.3)$ & $0.3(0.1-0.7)$ & 0.003 & & & & & & \\
\hline Older siblings & $0.8(0.5-1.4)$ & $0.6(0.3-1.1)$ & 0.315 & $1.0(0.6-1.5)$ & $0.7(0.3-1.6)$ & 0.530 & $1.2(0.7-2.1)$ & $1.5(0.6-3.7)$ & 0.654 \\
\hline \multicolumn{10}{|l|}{ Air pollution } \\
\hline Cooking with gas & $1.1(0.6-1.9)$ & $0.7(0.4-1.5)$ & 0.352 & $1.3(0.7-2.2)$ & $1.4(0.5-3.8)$ & 0.883 & $1.3(0.7-2.4)$ & $3.1(0.9-11.0)$ & 0.207 \\
\hline Mother smoking & $1.3(0.7-2.7)$ & $2.2(1.0-4.8)$ & 0.214 & $1.3(0.7-2.4)$ & $0.7(0.2-2.4)$ & 0.289 & $1.0(0.5-2.0)$ & $1.0(0.3-3.1)$ & 0.984 \\
\hline Father smoking & $1.2(0.7-2.2)$ & $1.1(0.5-2.3)$ & 0.788 & $1.0(0.6-1.6)$ & $0.7(0.3-1.9)$ & 0.529 & $1.0(0.5-2.0)$ & $0.9(0.3-2.7)$ & 0.814 \\
\hline \multicolumn{10}{|l|}{ Allergens } \\
\hline Pets & $1.0(0.6-1.7)$ & $0.6(0.3-1.2)$ & 0.171 & $1.0(0.7-1.5)$ & $0.6(0.3-1.3)$ & 0.188 & $0.9(0.6-1.6)$ & $2.5(1.0-6.0)$ & 0.043 \\
\hline \multicolumn{10}{|l|}{ Socioeconomic factors } \\
\hline Low maternal education ${ }^{+}$ & $1.0(0.6-1.6)$ & $1.1(0.6-2.0)$ & 0.802 & $1.0(0.6-1.5)$ & $0.6(0.3-1.3)$ & 0.233 & $1.6(1.0-2.8)$ & $2.2(0.9-5.2)$ & 0.552 \\
\hline Deprivation (Townsend) & $0.7(0.4-1.3)$ & $1.7(0.9-3.2)$ & 0.019 & $1.4(0.9-2.3)$ & $2.1(0.9-4.6)$ & 0.338 & $1.1(0.6-1.9)$ & $0.4(0.1-1.3)$ & 0.095 \\
\hline \multicolumn{10}{|l|}{ Perinatal and early life } \\
\hline Preterm (GA<37 weeks) & $0.3(0.03-2.2)$ & $1.5(0.4-6.4)$ & 0.125 & $1.0(0.4-2.5)$ & $2.5(0.7-8.6)$ & 0.130 & & & \\
\hline Low birthweight $(<2500 \mathrm{~g})$ & $3.3(0.8-13.5)$ & $2.0(0.3-12.6)$ & 0.566 & $1.0(0.4-2.4)$ & $1.7(0.4-6.3)$ & 0.440 & & & \\
\hline Young mother (<25 years) & $1.2(0.6-2.2)$ & $1.3(0.6-2.9)$ & 0.753 & $1.3(0.8-2.3)$ & $1.3(0.5-3.3)$ & 0.922 & $1.2(0.6-2.5)$ & $1.6(0.5-4.8)$ & 0.616 \\
\hline Breastfeeding & $0.8(0.5-1.3)$ & $0.7(0.3-1.3)$ & 0.694 & $1.1(0.7-1.7)$ & $0.6(0.3-1.4)$ & 0.191 & $0.5(0.3-0.9)$ & $0.4(0.2-1.1)$ & 0.683 \\
\hline Reflux in infancy & $1.4(0.7-2.7)$ & $1.5(0.6-3.4)$ & 0.920 & $0.9(0.6-1.5)$ & $1.9(0.6-5.7)$ & 0.206 & $0.9(0.5-1.8)$ & $0.6(0.2-1.6)$ & 0.370 \\
\hline \multicolumn{10}{|l|}{ Clinical factors } \\
\hline Rhinitis & $1.2(0.7-2.0)$ & $1.0(0.5-2.0)$ & 0.640 & $1.6(1.0-2.5)$ & $1.9(0.9-4.1)$ & 0.655 & $1.3(0.8-2.3)$ & $3.5(1.4-8.7)$ & 0.042 \\
\hline Hay fever ${ }^{\S}$ & & & & $1.1(0.5-2.0)$ & $1.9(0.7-2.3)$ & 0.270 & $4.3(1.6-11.4)$ & $5.3(1.5-19.1)$ & 0.722 \\
\hline Current eczema & $1.0(0.5-1.9)$ & $1.5(0.7-3.1)$ & 0.335 & $1.3(0.6-1.9)$ & $2.1(0.8-5.3)$ & 0.175 & $1.6(0.9-3.0)$ & $3.4(1.4-8.4)$ & 0.110 \\
\hline Cough triggered by: exercise & $1.1(0.5-2.7)$ & $3.8(1.7-8.8)$ & 0.010 & $1.3(0.8-2.1)$ & $1.9(0.8-4.2)$ & 0.409 & $1.4(0.7-2.5)$ & $4.1(0.5-10.9)$ & 0.034 \\
\hline aeroallergens & $0.3(0.03-2.7)$ & $1.9(0.4-8.0)$ & 0.123 & $1.4(0.7-2.8)$ & $3.0(1.1-8.0)$ & 0.113 & $5.2(2.0-13.6)$ & $8.3(2.5-27.6)$ & 0.370 \\
\hline laughter & $2.3(1.2-4.4)$ & $1.2(0.5-2.8)$ & 0.138 & $1.7(1.0-2.8)$ & $4.1(1.5-11)$ & 0.071 & $1.7(0.9-3.3)$ & $1.0(0.3-3.0)$ & 0.343 \\
\hline food & $1.3(0.7-2.6)$ & $0.7(0.2-1.8)$ & 0.187 & $1.0(0.5-1.9)$ & $1.0(0.3-3.6)$ & 0.953 & $1.9(0.8-4.6)$ & $0.5(0.1-4.5)$ & 0.237 \\
\hline Frequent colds ${ }^{f}$ & $0.8(0.4-1.4)$ & $0.9(0.4-2.0)$ & 0.640 & $1.1(0.5-2.3)$ & $1.0(0.3-3.8)$ & 0.906 & $4.8(1.3-17.8)$ & $1.8(0.2-18.0)$ & 0.366 \\
\hline Snoring & $0.8(0.5-1.4)$ & $2.1(1.0-4.4)$ & 0.020 & $1.9(1.1-3.0)$ & $2.1(0.9-5.2)$ & 0.777 & $1.3(0.7-2.3)$ & $3.4(1.1-10.6)$ & 0.105 \\
\hline Otitis at least once & $1.1(0.7-1.9)$ & $0.9(0.5-1.7)$ & 0.437 & $1.0(0.7-1.6)$ & $1.4(0.7-3.0)$ & 0.408 & $2.1(1.2-3.7)$ & $1.6(0.6-3.9)$ & 0.546 \\
\hline
\end{tabular}

RRR: relative risk ratio; GA: gestational age. " : Cough defined as night cough and no wheeze; ${ }^{\text {?: }} \mathrm{p}$-value from test for difference between associations of risk factors with cough and those with wheeze (Wald test); ${ }^{+}$: end of education of mother at age $\leqslant 16$ years; ${ }^{\S}$ : not inquired about in 1998 survey; ${ }^{f}:>6$ episodes of colds in the past year. 
children with respect to family history of asthma, parental smoking and atopic status, and concluded that children with isolated persistent cough without colds are unlikely to have asthma [15]. In our study we identified risk factors that were similar for cough and wheeze, such as family history of bronchitis and reflux, and others that differed (including ethnicity, sex, family history of asthma and day care attendance).

Prognosis of isolated night cough in children has received little attention in previous studies. Figure 1 shows that both cough and wheeze tracked more strongly with increasing age and that wheeze tracked more than cough. But we found no evidence that the risk of later wheeze was higher for children with isolated night cough than for asymptomatic children. In the first LRC (482 children born between 1985 and 1990, with no overlap with our study population), 37\% of 3-year-olds with cough continued to cough at age 6 years and 7\% developed wheeze [40]. This is similar to what we found from age 4 to 6 years in the second LRC: $42 \%$ continued coughing and $8 \%$ developed wheeze. Some studies investigated whether children with night cough progress to wheeze/ asthma, but did not assess persistence of cough [41, 42]. Among the 3252 children of the Prevention and Incidence of Asthma and Mite Allergy birth cohort, fewer than $10 \%$ of children with isolated night cough at age 2-7 years developed asthma at age 8 years and this was comparable to asymptomatic children [41]. The Tucson Children's Respiratory Cohort found that cough without colds at age 2 years persisted in $40 \%$ of children by age 6 years and in 35\% from age $6-11$ years. Risk factors for cough persistence were parental smoking from age 2-6 years and atopy from age 6-11 years [16]. We found that school children with isolated night cough had an increased risk for future wheeze if they also suffered from rhinitis, hay fever or cough triggered by typical asthma triggers. Overall, though, children with isolated night cough did not have a substantially higher risk of developing wheeze than asymptomatic peers.

Our study has several strengths. It is the first to compare risk factors and prognosis among children with isolated night cough and children with wheeze in a large cohort from the general population. It employed consistent methodology with standardised questions to assess symptoms and environmental factors in four surveys. It is also the first study to have investigated factors that predict persistence of isolated night cough and incidence of wheeze. Our cohort included a large proportion (20\%) of children of South Asian ethnic origin. South Asian ethnicity was a risk factor for cough, particularly in 1-year-olds, but not wheeze. The reason for this remains unclear, but could include the fact that South Asian children in the United Kingdom are more often atopic than white children, are more commonly exposed to indoor air pollution from cooking or heating and are in average more deprived [25]. Although we adjusted for all this, there may be residual confounding. Also, understanding of the word "wheeze" is poorer among parents from this ethnic group [43].

The study has also limitations. The main is its dependence on parental reports. Cough is more easily overheard by parents than wheeze, particularly at night. This might have affected prevalence estimates of night cough compared to wheeze, but should not have biased associations with risk factors or comparison of prognosis between groups. Similarly, lower response rates in later surveys might have affected prevalence of symptoms, but not association with risk factors or comparisons of prognosis. The fact that results were comparable between the main analysis that included all children who participated at least once, and the sensitivity analysis that focused on those who participated in all four surveys, is reassuring. Another limitation of our study is that we do not have data on the duration of night cough (i.e. whether this problem persisted for longer than 4 weeks). Also, we only studied two characteristics of CVA, as we could not assess physiological traits of CVA in this questionnaire-based study, namely eosinophilic inflammation, bronchial hyperreactivity and response to bronchodilators.

Overall, the results of our study contradict reports suggesting that children with recurrent dry cough have a variant form of asthma or risk to develop asthma in the future. Many of the earlier positive studies had methodological weaknesses, such as lack of comparison groups, small selective study populations [12, 19] or were conducted in adults $[20,21]$. The few that compared children with cough to children with wheeze and asymptomatic children in the same population found, as we did, little evidence for the existence of CVA $[16,22,23]$.

A number of alternative causes of chronic dry cough in children have been described. These include neuronal mechanisms and cough receptor hypersensitivity, especially nonspecific post-infectious hypersensitivity $[44,45]$. Children with different neurophenotypes show variable sensitivities to a range of cough challenge stimuli such as capsaicin [46]. Chronic upper respiratory disease of allergic or nonallergic origin can cause cough secondary to nocturnal mouth breathing or post-nasal drip with stimulation of pharyngolaryngeal receptors $[47,48]$. Gastroesophageal reflux can cause chronic cough in children through laryngeal soiling, pulmonary aspiration or vagal reflexes [49]. Chronic wet cough can be a sign of a more severe disease, such as a protracted bacterial bronchitis and disorders that affect bronchopulmonary clearance [3]. 
In summary, this population-based study found that risk factors for isolated dry night cough differed substantially from risk factors for wheeze and that children with isolated night cough were not more likely to develop wheeze in the future than asymptomatic children. Findings were slightly different for 1 -year-olds. Perhaps this is due to the general difficulty of diagnosing asthma at this age and because both cough and wheeze in infants are usually triggered by infections, whereas asthma later in childhood is often triggered by allergens or exercise. Overall, however, our study provides little support for the hypothesis that children with chronic dry cough at night have a variant form of asthma.

Acknowledgements: We thank the cohort participants and the parents of the LRC for completing the questionnaires. We thank Garyfallos Konstantinoudis (ISPM, University of Bern, Switzerland) for his contribution to the preparation of the figures. We thank Christopher Ritter (ISPM, University of Bern, Switzerland) for his editorial assistance.

Author contributions: C.E. Kuehni is the guarantor of the integrity of this work. All authors have revised the article for important intellectual content and finally approved of the version to be published, as well as agreed to be accountable for all aspects of the work. Conception and design: C.E. Kuehni and M. Jurca. Data acquisition: C.E. Kuehni and E.A. Gaillard. Data analysis: M. Jurca and B.D. Spycher. Interpretation of data: C.E. Kuehni, M. Jurca and M. Goutaki. Drafting the article: M. Jurca and C.E. Kuehni. Clinical input: E.A. Gaillard and P. Latzin.

Conflict of interest: None declared.

Support statement: All phases of this study were supported by the Swiss National Science Foundation (grants SNF PDFMP3 137033, 32003B_162820, 32003B_144068 and PZ00P3_147987) and Asthma UK (07/048). Funding information for this article has been deposited with the Crossref Funder Registry.

\section{References}

1 Chang AB, Robertson CF, Van Asperen PP, et al. A multicenter study on chronic cough in children: burden and etiologies based on a standardized management pathway. Chest 2012; 142: 943-950.

2 Spycher BD, Silverman M, Pescatore AM, et al. Comparison of phenotypes of childhood wheeze and cough in 2 independent cohorts. J Allergy Clin Immunol 2013; 132: 1058-1067.

3 Shields MD, Doherty GM. Chronic cough in children. Paediatr Respir Rev 2013; 14: 100-105.

4 Pratter MR. Unexplained (idiopathic) cough: ACCP evidence-based clinical practice guidelines. Chest 2006; 129: Suppl. 1, 220s-221s.

5 Brodlie M, Graham C, McKean MC. Childhood cough. BMJ 2012; 344: e1177.

6 Dodge R, Martinez FD, Cline MG, et al. Early childhood respiratory symptoms and the subsequent diagnosis of asthma. J Allergy Clin Immunol 1996; 98: 48-54.

7 Todokoro $\mathrm{M}$, Mochizuki $\mathrm{H}$, Tokuyama $\mathrm{K}$, et al. Childhood cough variant asthma and its relationship to classic asthma. Ann Allergy Asthma Immunol 2003; 90: 652-659.

8 Lougheed MD, Turcotte SE, Fisher T. Cough variant asthma: lessons learned from deep inspirations. Lung 2012; 190: $17-22$.

9 Johnson D, Osborn LM. Cough variant asthma: a review of the clinical literature. J Asthma 1991; 28: 85-90.

10 Glauser FL. Variant asthma. Ann Allergy 1972; 30: 457-459.

11 Corrao WM, Braman SS, Irwin RS. Chronic cough as the sole presenting manifestation of bronchial asthma. N Engl J Med 1979; 300: 633-637.

12 Yahav Y, Katznelson D, Benzaray S. Persistent cough a forme-fruste of asthma. Eur J Respir Dis 1982; 63: 43-46.

13 Pavord ID. Cough and asthma. Pulm Pharmacol Ther 2004; 17: 399-402.

14 Chen X, Peng WS, Wang L. Etiology analysis of nonspecific chronic cough in children of 5 years and younger. Medicine (Baltimore) 2019; 98: e13910.

15 Faniran AO, Peat JK, Woolcock AJ. Persistent cough: is it asthma? Arch Dis Child 1998; 79: 411-414.

16 Wright AL, Holberg CJ, Morgan WJ, et al. Recurrent cough in childhood and its relation to asthma. Am J Respir Crit Care Med 1996; 153: 1259-1265.

17 Thomson F, Masters IB, Chang AB. Persistent cough in children and the overuse of medications. J Paediatr Child Health 2002; 38: 578-581.

18 Turcotte SE, Lougheed MD. Cough in asthma. Curr Opin Pharmacol 2011; 11: 231-237.

19 Hannaway PJ, Hopper GD. Cough variant asthma in children. JAMA 1982; 247: 206-208.

20 Fujimura M, Ogawa H, Nishizawa $\mathrm{Y}$, et al. Comparison of atopic cough with cough variant asthma: is atopic cough a precursor of asthma? Thorax 2003; 58: 14-18.

21 Nakajima T, Nishimura Y, Nishiuma T, et al. Characteristics of patients with chronic cough who developed classic asthma during the course of cough variant asthma: a longitudinal study. Respiration 2005; 72: 606-611.

22 Hermann C, Westergaard T, Pedersen BV, et al. A comparison of risk factors for wheeze and recurrent cough in preschool children. Am J Epidemiol 2005; 162: 345-350.

23 Brooke AM, Lambert PC, Burton PR, et al. Recurrent cough: natural history and significance in infancy and early childhood. Pediatr Pulmonol 1998; 26: 256-261.

24 Kuehni CE, Brooke AM, Strippoli MP, et al. Cohort profile: the Leicester respiratory cohorts. Int J Epidemiol 2007; 36: 977-985.

25 Kuehni CE, Strippoli MP, Low N, et al. Wheeze and asthma prevalence and related health-service use in white and south Asian pre-schoolchildren in the United Kingdom. Clin Exp Allergy 2007; 37: 1738-1746.

26 Strippoli MP, Kuehni CE, Dogaru CM, et al. Etiology of ethnic differences in childhood spirometry. Pediatrics 2013; 131: e1842-e1849.

27 Kuehni CE, Strippoli MP, Spycher BD, et al. Lung function in the children of immigrant and UK-born south-Asian mothers. Eur Respir J 2015; 45: 1163-1166.

28 Asher MI, Keil U, Anderson HR, et al. International study of asthma and allergies in childhood (ISAAC) rationale and methods. Eur Respir J 1995; 8: 483-491. 
30 Townsend PPP, Beattie A. Health and deprivation: inequality and the North. Bristol, Croom Helm, 1988.

31 Smit HA, Pinart M, Anto JM, et al. Childhood asthma prediction models: a systematic review. Lancet Respir Med 2015; 3: 973-984.

32 Thompson BR. Dysanapsis-once believed to be a physiological curiosity-is now clinically important. Am J Respir Crit Care Med 2017; 195: 277-278.

33 Forno E, Weiner DJ, Mullen J, et al. Obesity and airway dysanapsis in children with and without asthma. Am J Respir Crit Care Med 2017; 195: 314-323.

34 Marchant JM, Masters IB, Taylor SM, et al. Evaluation and outcome of young children with chronic cough. Chest 2006; 129: 1132-1141.

35 Khoshoo V, Edell D, Mohnot S, et al. Associated factors in children with chronic cough. Chest 2009; 136: $811-815$.

36 Cook DG, Strachan DP. Health effects of passive smoking. 3. Parental smoking and prevalence of respiratory symptoms and asthma in school age children. Thorax 1997; 52: 1081-1094.

37 Burr ML, Anderson HR, Austin JB, et al. Respiratory symptoms and home environment in children: a national survey. Thorax 1999; 54: 27-32.

38 Hagerhed-Engman L, Bornehag CG, Sundell J, et al. Day-care attendance and increased risk for respiratory and allergic symptoms in preschool age. Allergy 2006; 61: 447-453.

39 Timonen KL, Pekkanen J, Korppi M, et al. Prevalence and characteristics of children with chronic respiratory symptoms in eastern Finland. Eur Respir J 1995; 8: 1155-1160.

40 Brooke AM, Lambert PC, Burton PR, et al. The natural history of respiratory symptoms in preschool children. Am J Respir Crit Care Med 1995; 152: 1872-1878.

41 Boudewijn IM, Savenije OE, Koppelman GH, et al. Nocturnal dry cough in the first 7 years of life is associated with asthma at school age. Pediatr Pulmonol 2015; 50: 848-855.

42 Oren E, Rothers J, Stern DA, et al. Cough during infancy and subsequent childhood asthma. Clin Exp Allergy 2015; 45: 1439-1446.

43 Michel G, Silverman M, Strippoli MP, et al. Parental understanding of wheeze and its impact on asthma prevalence estimates. Eur Respir J 2006; 28: 1124-1130.

44 Satia I, O’Byrne PM. Identifying a neurophenotype in severe asthma. Am J Respir Crit Care Med 2020; 201: $1024-1025$.

45 Belvisi MG, Birrell MA, Khalid S, et al. Neurophenotypes in airway diseases. insights from translational cough studies. Am J Respir Crit Care Med 2016; 193: 1364-1372.

46 Song WJ, Morice AH. Cough hypersensitivity syndrome: a few more steps forward. Allergy Asthma Immunol Res 2017; 9: 394-402.

47 Braunstahl GJ. United airways concept: what does it teach us about systemic inflammation in airways disease? Proc Am Thorac Soc 2009; 6: 652-654.

48 Cash H, Trosman S, Abelson T, et al. Chronic cough in children. JAMA Otolaryngol Head Neck Surg 2015; 141: 417-423.

49 Borrelli O, Marabotto C, Mancini V, et al. Role of gastroesophageal reflux in children with unexplained chronic cough. J Pediatr Gastroenterol Nutr 2011; 53: 287-292. 